\title{
Clinically Significant Variation of Paranasal Sinuses on CT-Scan
}

\author{
Maryam Faiz Qureshi, Ambreen Usmani
}

\section{ABSTRACT:}

Anatomical variations are not diseases and can be found in every individual. Due to the anatomical variations, the structural changes occur in nearby anatomical relations. By keeping in mind, the vast range of anatomical variations in nasal cavity and paranasal sinuses (PNS), every case of sinusitis must be planned carefully to avoid dreadful complications of surgical procedures. Sinus anatomical variations have been associated with the etiology of sinusitis. In this regard computed tomography (CT) imaging has become an important diagnostic tool. CT Scan imaging of nose and para nasal sinuses is mandatory in patients with history of sinusitis in order to evaluate the detailed anatomy which includes normal anatomy, anatomical variations, bony details and the extent of the disease pathology. Certain anatomical variants are supposed to be a causative factor for development of sinus pathology and hence it becomes compulsory for the radiologist to be aware of the anatomical variants of nasal cavity and PNS especially if the subject is considered for surgical intervention.

Key words: Anatomical Variations, Paranasal Sinuses (PNS), Nasal cavity, CT Scan, Functional Endoscopic Sinus Surgery (FESS).

\section{INTRODUCTION:}

Paranasal sinuses (PNS) are air-filled spaces present in specific bones of the skull. There are 4 pairs of paranasal sinuses which are named according to their location in which they are situated in the skull bones, which includes frontal sinus, maxillary sinus, ethmoid sinus, sphenoid sinus. Clinically, PNS are divided into 2 groups, the anterior group and the posterior group. Anterior group includes maxillary, frontal, and anterior ethmoidal, they all open together in the middle meatus and their ostia lie anterior to basal lamella of middle turbinate. Posterior group includes posterior ethmoidal sinuses which open in the superior meatus and the sphenoid sinus which open in the spheno-ethmoidal recess ${ }^{1}$.

Research show that the anatomy of PNS is variable and complex. CT PNS is choice of investigation in evaluating PNS anatomy, pathology and the anatomical variations. The anatomical variations disturbing osteomeatal complex (OMC) includes Deviated nasal septum (DNS), concha bullosa (CB) bent middle turbinate, agger nasi cells and haller cells. These OMC anatomical variants can cause meatal narrowing and even obstruction of sinus. Knowledge of the anatomical variations does reduce the surgical complication rates during Functional Endoscopic Sinus Surgery (FESS), and helps explain recurrence of disease. It also allows one to change the operative technique for the benefit of patient. CT PNS has vital role in presurgical evaluation of minimally invasive FESS 2,3,4,5,6,7,8,9.

Maryam Faiz Qureshi
MPhil Postgraduate Student, Department of Anatomy
I Bahria University Medical and Dental College, Karachi
I Email: qureshimaryam25@gmail.com
I Ambreen Usmani
I Senior Professor, HOD Department of Anatomy and
Principal, Bahria University Medical and Dental College, |
I Karachi
I Received: 17-Dec-2019
Accepted: 26-Feb-2020

It is necessary to identify the clinical and surgical importance of anatomical variants of PNS, certain anatomical variants are supposed to be causative factor for development of sinus pathology and hence it becomes compulsory for the radiologist to be alert of the anatomical variants of PNS especially if the subject is candidate for $\mathrm{FESS}^{3,4,6,10,11}$.

The important ethmoid air cells which are included in anterior group are: agger nasi cells, ethmoid bulla, supraorbital cells, frontoethmoidal cells, haller cells ${ }^{1}$. The ethmoid air sinuses play a crucial role in FESS. The posterior ethmoids and the sphenoid sinuses can be accessed via the anterior ethmoid cells. Anterior ethmoidectomy helps improve frontal air sinus drainage hence minimizing the need for opening the frontal sinus during surgery ${ }^{12,13}$. Variations in the pneumatization of ethmoid sinuses may result in the disturbance of sinus ventilation and sinus drainage pathway. These can be the etiological factor for sinusitis and spread of infection to adjacent structures ${ }^{13,14}$.

The coronal views of CT scan are best for the sphenoid and the ethmoid cell variants such as the onodi cells or sphenoethmoidal cells. The modification and advancement of computed tomography has granted extensive assessment of patient's paranasal sinuses thus providing a guide map for FESS surgeons to operate effectively ${ }^{15,5,13}$. In a study conducted in Egypt it was reported that the frequency of agger nasi cells and CB were equally frequent (30.6\%), and Haller cells were detected in $11.2 \%$. Variations of uncinate process were detected in $18.1 \%$, and the large ethmoid bulla was detected in $10 \%{ }^{16}$.

Whatever may be the diagnosis, but for understanding of anatomical relations of paranasal sinuses, CT Scan of Para nasal sinus is mandatory before performing sinus surgery. This is to avoid chance of complications while performing the procedure. Patients having history of chronic sinusitis and who are not responding to medical therapy, computed tomography should be performed for the possible 
identification of anatomical variants. In order to prevent harmful complications such as cerebrospinal fluid (CSF) leak, meningitis, or blindness, this prevention will decrease the burden of disease, patient disability and patient morbidity, so a detailed knowledge of the possible anatomical variations is essential ${ }^{17}$. Pneumatization (formation of air cells) of turbinate referred as concha bullosa (CB) is a normal anatomical variant of PNS. CB is classified into extensive $\mathrm{CB}$, bulbous $\mathrm{CB}$, lamellar $(\mathrm{CB})$ and out of these middle turbinate $\mathrm{CB}$ has been identified as a possible causative factor in sinusitis ${ }^{18,7}$.

As a number of lateral nasal wall diseases cannot be recognized and identified by endoscope, so with this regard computed tomography must be performed even when the diagnostic nasal endoscopic finding is insignificant, provided that the history and clinical findings suggest the presence of some disease ${ }^{19}$. The anatomical variations of lateral nasal wall and PNS are surgically and patho-physiologically important because they narrow the drainage pathway, impair the mucociliary function of the para nasal sinuses, which in turn leads on to stagnation of secretions, then infection and inflammation of the mucosa lining the sinuses occurs. Diseases in severely pneumatized sinuses direct on to exposure of important structures like Optic nerve, Internal Carotid artery, and anterior cranial fossa of the brain, to infection and inflammation, and also increases risk of injury during surgical procedure. Hence, CT Scan imaging of nose and PNS is mandatory in patients with history of sinusitis, to evaluate the detailed anatomy (normal anatomy, anatomical variations, bony details and the extent of the disease pathology) that are commonly encountered in the osteomeatal complex (OMC), and lateral nasal wall ${ }^{20,3,4,21,7,8}$. Frequent and extensive application of functional endoscopic sinus surgery (FESS) with experience makes it essential to know the complex anatomy and the pathology of PNS very well and thoroughly before surgery. The importance of paranasal sinus computed tomography in terms of identifying and determining anatomical variations of PNS before FESS, helps in predicting the complications that can occur during surgery has been highlighted $22,3,4,6$.

\section{METHODOLOGY:}

The overall methodology was commenced by the following steps mentioned below;

1. Review of various articles related with the topic

2. Extraction of articles

3. Data gathered

4. Analysis and comparison of findings

5. Conclusion

After following above mentioned steps, a comprehensive literature search was done using Google Scholar, Medline, PubMed, and Pakmedinet from the year 2009 onwards using keywords like anatomical variations, CT-scan, FESS, nasal cavity and paranasal sinuses. For Ancient literature books and other clinical guidelines of international organizations were also reviewed for relevant references. The analysis of the data was done by regional analysis technique, and narrative synthesis methodology was used to synthesize overall review findings.

\section{Literature Review:}

The paranasal sinuses (PNS) form a complex variable unit of 4 paired air-filled spaces at the opening of the proximal airway. The development of PNS starts from furrows and ridges in the lateral wall of nasal cavity during $8^{\text {th }}$ week of development, and sinuses continue their formation as air cells within the cavities until early adulthood from the age of 20 to 25 years. Each sinus is named according to the skull bone in which they are located ${ }^{1,23}$.

Paranasal sinuses include frontal sinus, maxillary sinus, ethmoid sinus and the sphenoid sinus, maxillary sinus is largest of all ${ }^{1}$. Radiologic evidence of various sinuses appears by the age of 4-5 months after birth (maxillary sinus), 1 year of age (ethmoid sinus), 6 years of age (frontal), and 4 years of age (sphenoid). These 4 pairs of paranasal sinuses perform various important functions which are, air conditioning of the inspired air, improves the voice, provides quality and resonance to voice, act as thermal insulators to provide protection to the delicate structures which are present in the orbit and cranium from variable changes of intranasal temperature. It also, lightens the skull bones, provide extended surface for olfaction, offers immunologic defense against microbes, act as buffers against trauma and thus protect brain against any kind of injury ${ }^{1,24,11}$.

Hippocrates in 5th century B.C. stated "In a person having a painful spot in head, with intense headaches, pus or fluid running from the nose removes the disease" which may be referred as sinusitis. Sinusitis is the inflammation or swelling of mucosal lining of PNS, and the spaces that secretes mucus which is necessary for the nasal passages to work effectively ${ }^{25}$. Sinusitis occurs when there is impaired mucociliary apparatus function with meatal narrowing or even obstruction, excessive mucus production or excessive mucus build up, stagnant mucous collection results in the sinuses becoming inflamed. Sinusitis can be acute or chronic, it can occur due to various reasons, such as viral, bacterial, fungal infection, allergic reactions, or even it can occur due autoimmune reactions ${ }^{1,67}$.

Frontal sinuses are mostly paired and lobulated in shape. They are commonly symmetrical in shape, with presence of septum between the pair of frontal sinuses. Sometimes one or both of the sinuses may be missing. Frontal sinuses are not present at the time of birth, their development starts at the age of two years and reaches full size early adulthood. The frontal sinuses are located in the posterior most part of supercilliary arches, between the external and internal tables of frontal bone. Presence of bilateral frontal sinus was reported in $(78.6 \%)$ subjects and presence of unilateral 
frontal sinus was found to be present in (17.9\%) subjects $^{23}$.

The most common anatomical variations of maxillary sinus were reported as pneumatization of the sinus and sinus septa. The prevalence of disease process in maxillary sinus was ranged from $7.5 \%$ to $66 \%{ }^{15}$. The most frequent pathological findings of the maxillary sinus were sinus opacification, sinusitis, and mucosal thickening ${ }^{26,13}$.

A study conducted in Philippines reported that most of the patients with sinusitis were males between age group of 31 to 40 years $^{16}$. Most common anatomical variants were DNS, $\mathrm{CB}$, agger nasi cells, and haller cells. Significant prevalence of anatomical variants of PNS was found among patients with sinus infection ${ }^{27,3,5,8,24,9}$.

The study reported that the prevalence of bilaterally present agger nasi cells was found to be $100 \%{ }^{28}$. The success rate of FESS is completely related to the knowledge of complex sinus anatom ${ }^{28}$. Surgeon should be concerned about the anatomical variants of PNS for every patient before going for $\mathrm{FESS}^{28,3,4,6}$.

The roof of ethmoid sinus is of great importance having close relationship with anterior cranial fossa. The anterior ethmoidal artery lies in the rostrum of ethmoid sinus, it is an anatomical reference point that goes from orbital region to anterior cranial fossa. Its location is of great importance during FESS. Adequate presurgical evaluation with CT scan imaging technique is important to assess the ethmoidal roof and its nearby structures ${ }^{29,30}$.

Altered nasal septum occludes most of the nasal cavity considered as DNS. It is of three types osseous DNS, cartilaginous DNS and osteocartilaginous DNS type. DNS may result in compression of turbinate causing blockage of sinus drainage pathway and increases chances of infection and inflammation of the sinuses ${ }^{31,5}$. Deviated nasal septum was found in $62 \%$ of cases. The close proximity of PNS to important structures and neurovascular bundle such as optic nerve, orbit, skull base, and internal carotid artery stresses on the need of identification of anatomical variations of PNS in order to avoid the serious complications of surgical procedure $^{31,30,24}$.

Usman studied anatomical variations of PNS and nasal cavity in which DNS was found in $31 \%$ of cases, CB was present in $18.9 \%$ of cases whereas variation in uncinate process was reported in $12 \%$ of cases. Haller cells and aggernasi cells were found in $3.7 \%$ and $6.8 \%$ of patients respectively. Pneumatization of nasal septum was observed in only one patient with prevalence of $0.7 \%$. Pneumatized turbinates were not reported in any patient, although pneumatization of uncinate process was observed in $2.2 \%$ of cases. Paradoxical middle turbinate was present in $9 \%$ of cases. Septal spur was seen in 3\% of cases. Fifteen patients observed had more than single anatomical variants. In $2.2 \%$ of cases CB and haller cell both were present. Variation in uncinate process with paradoxical medial turbinate were seen in $2.2 \%$. In $5.3 \%$ of cases DNS was present along with bony spur and in $1.5 \%$ of cases pneumatized nasal septum with pneumatized uncinate process was reported ${ }^{32}$.

The structural morphology of paranasal sinuses shows vast diversity. They all vary in size, shape, morphology and count of the septa present, as in sphenoid sinus the MS which is main septum, and AS which is additional septum. The sphenoid sinus is related with important anatomical structures with respect to their walls, including both vascular and nervous relations, in addition to the anatomical organization of the sphenoid sinuses which is of great significance in the various surgical procedures such as FESS. CT imaging technique is one of the most accurate methods for imaging of the paranasal sinuses to visualize various structures along with their extent and depth. This method allows doctors to distinguish the variations in the anatomical relations of the PNS, due to the obvious clear-cut illustration of the bony structures $^{33,3,4,21,6}$.

Sphenoidal sinus variation is broadly used in skull base surgeries in a common surgical procedure called functional endoscopic sinus surgery. FESS is one of the best choices in a variety of surgeries such as endoscopic orbital surgery, sinonasal tumors. Various nerves and vessels are present near sphenoid sinus which are at danger during surgical procedure. These structures will be at risk of injury during surgery because of anatomical variations which includes protrusion, dehiscence, and pneumatization. CT scan imaging is a useful technique for the detection of PNS anatomical variants. Besides diagnostic value, CT scan imaging is valuable for risk assessment factors produced by anatomical variations of PNS $^{34,3,4,13}$.

In 1904 the posterior ethmoidal air cells called onodi cells were first reported by Adolf Onodi. The reported incidence was $10 \%$ in Indian population. It lies superior to sphenoid sinus. Its close proximity to optic nerve, internal carotid artery makes its diagnosis imperative prior to FESS. Variants of optic nerve in relation to sphenoidal sinus are classified as type 1: optic nerve is near to sphenoid sinus without indentation, type 2: nerve is near to sphenoid sinus indenting the wall, type 3: nerve courses through sphenoid sinus and type 4: nerve is near to sphenoid sinus and posterior ethmoidal cell $^{10,35}$.

Coronal plane computerized tomographic (CT) scanning has markedly improved the imaging of complex PNS anatomy as compared to sinus radiographs. Increasingly subtle bony anatomical variations and mucosal abnormalities of this region are being detected. Computerized tomography (CT) offers the gold standard in terms of imaging the extent of disease pathology and the fine detailed anatomy of paranasal sinus ${ }^{35,3,4,21,5,6,13,24}$. Neither plain X-rays nor Magnetic Resonance Imaging (MRI) offer optimal information in this respect ${ }^{35,3}$.

The height of lateral cribriform plate lamella determines the 
depth of the olfactory fossa. In 1962 Kero classified this height as: Type 1: $1-3 \mathrm{~mm}$, type $2: 4-7 \mathrm{~mm}$, and type $3: 8$ $-16 \mathrm{~mm}$. The increased depth of olfactory fossa produces a way for an increased chance of accidental injury to anterior cranial fossa during FESS, trauma and also in tumor erosion $^{10,36}$.

CT imaging is important to evaluate various pathologies of nasal cavity and PNS. It also helps to assess the fine bony details related to PNS, anatomical variants of PNS, and disease progress of PNS. Coronal high-resolution CT of the sinuses has become widely accepted as a necessary part of the preoperative evaluation of patients scheduled for FESS. CT scanning is better in identifying anatomical landmarks of PNS preoperatively and thereby reduces the complications of FESS. CT imaging technique is now established as the overall best method for evaluation of patients who are suspected of having a complex anatomy and any aggressive lesion of the paranasal sinuses (PNS) ${ }^{3,4,5,6,37,38}$.

Literature has revealed that the conventional radiographs are of limited diagnostic use in evaluation of PNS diseases and modern imaging techniques like $\mathrm{CT}$ and MRI provide greater detail about the exact location, the extent of PNS disease and also helps in better understanding of complex anatomy, diagnosis and treatment plan of sinus diseases. It is also stated that CT is better than MRI in knowing the finer bony details, anatomical variations and fibro osseous lesions of PNS $^{4,39}$.

Literature search has also reported that the CT imaging proves to be a necessary tool in case of nasal pathologies as it provides a guide to the ENT surgeon and it also illustrates the whole pathway along with the anatomical variations of the individual and warns one of any existing or threatening complication of FESS 4,6,40,41. $^{\text {. }}$

It was concluded that use of CT scan is the most accurate approach in understanding the anatomical variations and diagnosing the diseases of $\mathrm{PNS}^{3,4,5,6,13,21,24}$. Surgeon must keep in mind that, remove only as much as required and preserve as much as possible, this has been the most important instruction of FESS. The anatomy of the nasal cavity and PNS is variable in every individual so in order to prevent various surgical or iatrogenic complications such as CSF leak, surgeon must have good idea about anatomical variants of the subject. CT is the investigation of choice particularly for the patients who are scheduled for FESS, assisting the ENT surgeon to understand the complex and variable anatomy affecting the paranasal sinus region. Thus, it is termed as "ROAD MAP OF FESS" "4,42,43,44,45,46, The contribution of anatomical variants has been questioned as the variants are

\section{Comparison:}

\begin{tabular}{|c|c|c|c|c|}
\hline Country & Year & Author name & Study type & Outcome \\
\hline Poland & 2009 & Rysz M, Bakoñ L ${ }^{52}$ & Retrospective & Haller cells: $13 \%$, Bony septa per sinus: $26 \%$ \\
\hline Malaysia & 2010 & Vincent TE, Gendeh BS ${ }^{51}$ & Retrospective & DNS: $46.7 \%, \mathrm{CB}: 62.9 \%$ (unilateral), CB:37.1\% (bilateral) \\
\hline Nigeria & 2011 & Amusa YB, Eziyi JA, et al. ${ }^{54}$ & Cadaveric & $\begin{array}{l}\text { Haller cells: } 4 \% \text {, Onodi cells: } 4 \% \text {, Frontal cells: } 8 \% \text {, Supra } \\
\text { orbital cells: } 4 \%\end{array}$ \\
\hline Italy & 2012 & Fadda GL, Rosso S, et al. ${ }^{49}$ & Prospective & $\begin{array}{l}\text { DNS: } 58.5 \% \text {, Agger nasi cell: } 24.3 \% \text {, CB: } 49.3 \% \text {, Halle cells: } \\
22.8 \% \text {, Onodi clls: } 8.5 \%\end{array}$ \\
\hline Pakistan & 2013 & Adeel M, Rajput MS et al. ${ }^{55}$ & Retrospective & DNS: $26 \%, \mathrm{CB}: 18.2 \%$ \\
\hline Oman & 2014 & Al-Abri R, Bhargava D et al. ${ }^{53}$ & Prospective & $\begin{array}{l}\text { DNS: } 80 \% \text {, Agger nasi cells: } 49 \% \text {, Haller cells: } 24 \% \text {, Onodi } \\
\text { cells: } 7.5 \% \text {, CB: } 49 \% \text {, Olfactory fossa: Type } 1-30 \% \text {, Type } 2- \\
34 \% \text {, Type } 3-36 \%\end{array}$ \\
\hline India & 2015 & Tiwari R, Goyal $\mathrm{R}^{50}$ & Prospective & $\begin{array}{l}\text { DNS: } 88.2 \% \text {, CB: } 76.4 \% \text {, Agger nasi cells: } 7 \% \text {, Haller cells: } \\
3.5 \% \text {, Onodi cells: } 1.6 \%\end{array}$ \\
\hline Turkey & 2016 & Dasar U, Gokce $\mathrm{E}^{19}$ & Prospective & Agger nasi cells: $74.8 \%$, CB: $67.5 \%$, DNS: $59.5 \%$ \\
\hline South India & 2017 & Gouripur K, et al. ${ }^{16}$ & Prospective & $\begin{array}{l}\text { Agger nasi cells: } 96 \%, \text { CB: } 67.5 \% \text {, DNS: } 70 \% \text {, Onodi cells: } \\
6 \% \text {, Haller cells: } 14 \%\end{array}$ \\
\hline Egypt & 2017 & $\begin{array}{l}\text { Alsowey AM, Abdulmonaem } \\
\text { G et } \mathrm{al}^{15}\end{array}$ & Prospective & $\begin{array}{l}\text { DNS: } 48.8 \% \text {, Agger nasi cells: } 30.6 \% \text {, CB }: 30.6 \% \text {, Haller } \\
\text { cells: } 11.2 \% \text {, Uncinate process variations: } 18.1 \% \text {, Large } \\
\text { ethmoid bulla: } 10 \%\end{array}$ \\
\hline India & 2018 & $\begin{array}{l}\text { Kalaiarasi R, Ramakrishnan } \\
\mathrm{V} \text { et } \mathrm{al}^{17}\end{array}$ & Retrospective & CB: $54.7 \%$ bilateral, $\mathrm{CB}: 45.3 \%$ unilateral \\
\hline Philippines & 2018 & Espinosa W, Genito R et al. ${ }^{26}$ & Retrospective & $\begin{array}{l}\text { Agger nasi cells: } 78.3 \% \text {, Haller cells } 41.6 \% \text {, DNS: } 20.0 \% \text {, } \\
\text { CB: } 11.7 \%\end{array}$ \\
\hline Turkey & 2019 & Yazici D. ${ }^{47}$ & Retrospective & $\begin{array}{l}\text { Haller cells: } 19.3 \% \text {, Onodi cells: } 19 \% \text {, DNS: } 48.7 \% \text { (right), } \\
\text { DNS: } 51.7 \% \text { (left), Agger nasi cells: } 82 \%, \text { CB: } 45.3 \%\end{array}$ \\
\hline Nepal & 2019 & $\begin{array}{l}\text { Shrestha KK, Acharya K et } \\
\text { al. }^{48}\end{array}$ & Prospective & $\begin{array}{l}\text { DNS: } 64.5 \% \text {, CB: } 19.7 \% \text {, Agger nasi: } 18.4 \% \text {, Septal } \\
\text { pneumatization:6.5\%, Onodi cell: } 3.9 \% \text {, Haller cell: } 2.6 \%\end{array}$ \\
\hline
\end{tabular}


equally prevalent in asymptomatic patients and in symptomatic patients of sinusitis. CT-scan can play an important role in formal preoperative assessment of normal anatomy along with variations of paranasal sinuses and nasal cavity that can have great impact over surgical planning and decreasing the ratio of surgical complications.

\section{CONCLUSION:}

Anatomic structural variations of nasal cavity and PNS have a practical importance during surgical procedures led on the sinuses by otolaryngologists.

The importance of this review is to identify the anatomical variations of PNS and nasal cavity on imaging techniques and their effective utilization while performing the minimal invasive FESS. CT-scan plays a fundamental role in the diagnosis of anatomical variations as well as of various diseases, for a better understanding in the decision making about clinical therapeutic and surgical approaches, acting as an indispensable aid for a better performance and success rate of less invasive operative techniques such as FESS.

\section{REFERENCES:}

1. Dhingra PL, Dhingra S. Diseases of Ear, Nose and ThroatE-Book. Elsevier Health Sciences. 2014; ED.5.

2. Jagannathan D, Kathirvelu G, Hithaya F. Prevalence of variant anatomy of paranasal sinuses in computed tomography and its correlation to sinusitis. IOSR J Dent Med Sci. 2017; 16:17.

3. Turna Ö, Aybar MD, Karagöz Y, Tuzcu G. Anatomic Variations of the Paranasal Sinus Region: Evaluation with Multidetector CT. Istanbul Medical Journal. 2014;15(2).

4. Hoang JK, Eastwood JD, Tebbit CL, Glastonbury CM. Multiplanar sinus CT: a systematic approach to imaging before functional endoscopic sinus surgery. American journal of roentgenology. 2010;194(6): 527-36.

5. Shpilberg KA, Daniel SC, Doshi AH, Lawson W, Som PM. CT of anatomic variants of the paranasal sinuses and nasal cavity: poor correlation with radiologically significant rhinosinusitis but importance in surgical planning. American Journal of Roentgenology. 2015;204(6):1255-60.

6. Bolger WE, Parsons DS, Butzin CA. Paranasal sinus bony anatomic variations and mucosal abnormalities: $\mathrm{CT}$ analysis for endoscopic sinus surgery. The Laryngoscope. 1991;101(1):56-64.

7. Shrikrishna BH, Jyothi AC, Sanjay G, Sandeep Samson G, Shrikrishna BH. Relationship of concha bullosa with osteomeatal unit blockage. tomographic study in 200 patients. Journal of Evolution of Medical and Dental Sciences. 2013;2(22):3906-15.

8. Fadda GL, Rosso S, Aversa S, Petrelli A, Ondolo C, Succo G. Multiparametric statistical correlations between paranasal sinus anatomic variations and chronic rhinosinusitis. Acta Otorhinolaryngologica Italica. 2012;32(4):244.

9. Shrestha KK, Acharya K, Joshi RR, Maharjan S, Adhikari D. Anatomical variations of the paranasal sinuses and the nasal cavity. Nepal Medical College Journal. 2019;21(1):7-11.
10. Reddy UD, Dev B. Pictorial essay: Anatomical variations of paranasal sinuses on multidetector computed tomographyHow does it help FESS surgeons? The Indian journal of radiology \& imaging. 2012;22(4):317-24.

11. Shokri A, Faradmal MJ, Hekmat B. Correlations between anatomical variations of the nasal cavity and ethmoidal sinuses on cone-beam computed tomography scans. Imaging Science in Dentistry. 2019;49(2):103-13.

12. Jankowski R, Nguyen DT, Poussel M, Chenuel B, Gallet P, Rumeau C. Sinusology. European annals of otorhinolaryngology, head and neck diseases. 2016;133(4): 263-268.

13. Zinreich, S. J., Stammberger, H., Bolger, W., Solaiyappan, M., \& Ishii, M. Advanced CT imaging demonstrating the bulla lamella and the basal lamella of the middle turbinate as endoscopic landmarks for the anterior ethmoid artery. Rhinology online. 2019;7(2):32-43.

14. Gupta S, Gurjar N, Mishra HK. Computed tomographic evaluation of anatomical variations of paranasal sinus region. Int J Res Med Sci. 2016; 4:2909-2913.

15. Alsowey AM, Abdulmonaem G, Elsammak A, Fouad Y. Diagnostic performance of multidetector computed tomography (MDCT) in diagnosis of sinus variations. Polish journal of radiology. 2017; 82:713-25.

16. Gouripur K, Kumar U, Janagond AB, Elangovan S, Srinivasa $\mathrm{V}$. Incidence of sinonasal anatomical variations associated with chronic sinusitis by CT scan in Karaikal, South India. International Journal of Otorhinolaryngology and Head and Neck Surgery. 2017;3(3):576-9.

17. Kalaiarasi R, Ramakrishnan V, Poyyamoli S. Anatomical Variations of the Middle Turbinate Concha Bullosa and its Relationship with Chronic Sinusitis: A Prospective Radiologic Study. International archives of otorhinolaryngology. 2018;22(03):297-302.

18. Pynnonen MA, Gillespie MB, Roman B, Rosenfeld RM, Tunkel DE, Bontempo L, Brook I, Chick DA, Colandrea M, Finestone SA, Fowler JC. Clinical practice guideline: evaluation of the neck mass in adults. Otolaryngology-Head and Neck Surgery. 2017;157: S1-30.

19. Dasar U, Gokce E. Evaluation of variations in sinonasal region with computed tomography. World journal of radiology. 2016;8(1):98-108.

20. Tiwari R, Goyal R. Study of anatomical variations on CT in chronic sinusitis. Indian Journal of Otolaryngology and Head \& Neck Surgery. 2015;67(1):18-20.

21. Turkdogan FT, Turkdogan KA, Dogan M, Atalar MH. Assessment of sphenoid sinus related anatomic variations with computed tomography. The Pan African Medical Journal. DOI:10.11604/pamj.2017.27.109.7391

22. Arshad F, Begum S, Jan S. Volumetric Analysis of Frontal Sinuses by Using Cone Beam Computed Tomography in South Indian Population Scholars Journal of Dental Sciences (SJDS) ISSN 2394-4951 (Print). Imaging. 2018; 3:2-9.

23. Mathuram AC, Aiyappan SK, Agarwal S, Raveendran NH, Valsala VS. Assessment of Sinonasal Anatomical Variants using 128-Slice MDCT in Patients with Chronic Rhinosinusitis. Radiology. 2019;4(2):120-26.

24. Shoib SM, Viswanatha B. Association between symptomatic deviated nasal septum and sinusitis: a prospective study. Res Otolaryngol. 2016;5(1):1-8 
25. Ata-Ali J, Diago-Vilalta JV, Melo M, Bagán L, Soldini MC, Di-Nardo C, Ata-Ali F, Mañes-Ferrer JF. What is the frequency of anatomical variations and pathological findings in maxillary sinuses among patients subjected to maxillofacial cone beam computed tomography? A systematic review. Medicina oral, patologia oral y cirugia bucal. 2017;22(4):400-9.

26. Espinosa W, Genito R, Ramos RZ. Anatomic variations of the nasal cavity and paranasal sinus and their correlation with chronic rhinosinusitis using Harvard staging system. J Otolaryngol ENT Res. 2018;10(4):190-3.

27. Alshaikh N, Aldhurais A. Anatomic variations of the nose and paranasal sinuses in saudi population: computed tomography scan analysis. The Egyptian Journal of Otolaryngology. 2018;34(4):234-41.

28. Muñoz-Leija MA, Yamamoto-Ramos M, Barrera-Flores FJ, Treviño-González JL, Quiroga-Garza A, Méndez-Sáenz MA, Campos-Coy MA, Elizondo-Rojas G, Guzmán-López S, Elizondo-Omaña RE. Anatomical variations of the ethmoidal roof: differences between men and women. European Archives of Oto-Rhino-Laryngology. 2018;275(7):1831-36.

29. Ribeiro BN, Muniz BC, Marchiori E. Preoperative computed tomography evaluation of the paranasal sinuses: what should the physician know? -pictorial essay. Radiologia brasileira. 2019;52(2):117-22.

30. Kumar P, Rakesh BS, Prasad R. Anatomical variations of sinonasal region, a coronal CT scan study. Int J Contemporary Med Res. 2016;3(9):2601-04.

31. Usman R, Hassan NH, Hamid K, Soban M, Darira M, Saifullah. Role of CT- Scan in Assessment of Anatomical Variants of Nasal Cavity and Paranasal Sinuses. JBUMDC 2016;6(4):219-22

32. Jaworek-Troæ J, Zarzecki M, Mróz I, Troæ P, Chrzan R, Zawiliñski J, Walocha J, Urbanik A. The total number of septa and antra in the sphenoid sinuses-evaluation before the FESS. Folia Medica Cracoviensia. 2018.

33. Joghataei MT, Hosseini A, Ansari JM, Golchini E, Namjoo Z, Mortezaee K, Pirasteh E, Dehghani A, Nassiri S. Variations in the Anatomy of Sphenoid Sinus: A Computed Tomography Investigation. Journal of Pharmaceutical Research International. 2019:1-7.

34. Bagul M. Computed tomography study of paranasal sinuses pathologies. Int J Sci Stud. 2016;4(4):12-6.

35. Jagannathan D, Kathirvelu G, Hithaya F. Prevalence of variant anatomy of paranasal sinuses in computed tomography and its correlation to sinusitis. IOSR J Dent Med Sci. 2017; 16:17.

36. Kandukuri R, Phatak S. Evaluation of sinonasal diseases by computed tomography. Journal of clinical and diagnostic research: JCDR. 2016;10(11):TC09.

37. Ribeiro BN, Muniz BC, Marchiori E. Preoperative computed tomography evaluation of the paranasal sinuses: what should the physician know? -pictorial essay. Radiologia brasileira. 2019;52(2):117-22.

38. Yousef, M., Sulieman, A., Hassan, H., Ayad, C., Bushara, L., Saeed, A., \& Ahmed, B. Computed tomography evaluation of paranasal sinuses lesions. Sudan Medical Monitor. 2014;9(3),123-26.

39. Mirza, S.H., Kapoor, P. Advance of CT scan as an important imaging tool in evaluation of nasal polypoidal masses. ARIPEX - Indian Journal of Research. 2018;7(12):2250-1991.
40. Mokhasanavisu VJ, Singh R, Balakrishnan R, Kadavigere R. Ethnic Variation of Sinonasal Anatomy on CT Scan and Volumetric Analysis. Indian Journal of Otolaryngology and Head \& Neck Surgery. 2019;1-8.

41. Jaworek-Troæ J, Zarzecki M, Mróz I, Troæ P, Chrzan R, Zawiliñski J, Walocha J, Urbanik A. The total number of septa and antra in the sphenoid sinuses-evaluation before the FESS. Folia Medica Cracoviensia. 2018;8(3),67-81.

42. Yousef, M., Sulieman, A., Hassan, H., Ayad, C., Bushara, L., Saeed, A., \& Ahmed, B. Computed tomography evaluation of paranasal sinuses lesions. Sudan Medical Monitor. 2014;9(3),123-26.

43. Gohar MS, Niazi SA, Niazi SB. Functional Endoscopic Sinus Surgery as a primary modality of treatment for primary and recurrent nasal polyposis. Pak J Med Sci. 2017;33(2):380382

44. Akhter S, Zia S, Zafar R. Endoscopic repair of cerebrospinal fluid rhinorrhoea in a developing country. J Pak Med Assoc. 2012;62(9):972-4.

45. Adil R, Qayyum A. Correlation of x rays and computed tomography in paranasal sinus diseases. PAFMJ.2011; 61(3):413-7.

46. Sajid T, Kazmi HS, Shah SA, Ali Z, Khan F, Ghani R, Khan J. Complications of Nose and Paranasal Sinus Disease. J Ayub Med Coll Abbottabad. 2011;23(3):56-9.

47. Yazici D. The Analysis of Computed Tomography of Paranasal Sinuses in Nasal Septal Deviation. Journal of Craniofacial Surgery. $2019 ; 30(2)$ : e143-7.

48. Shrestha KK, Acharya K, Joshi RR, Maharjan S, Adhikari D. Anatomical variations of the paranasal sinuses and the nasal cavity. Nepal Medical College Journal. 2019;21(1):7-11.

49. Fadda GL, Rosso S, Aversa S, Petrelli A, Ondolo C, Succo G. Multiparametric statistical correlations between paranasal sinus anatomic variations and chronic rhinosinusitis. Acta Otorhinolaryngologica Italica. 2012;32(4):244.

50. Tiwari R, Goyal R. Study of anatomical variations on CT in chronic sinusitis. Indian Otolaryngol Head Neck Surg. 2015;67(1):18-20.

51. Vincent TE, Gendeh BS. The association of concha bullosa and deviated nasal septum with chronic rhinosinusitis in functional endoscopic sinus surgery patients. Med J Malaysia. 2010;65(2):108-1.

52. Rysz M, Bakoñ L. Maxillary sinus anatomy variation and nasal cavity width: structural computed tomography imaging. Folia morphologica. 2009;68(4):260-4.

53. Al-Abri R, Bhargava D, Al-Bassam W, Al-Badaai Y, Sawhney S. Clinically significant anatomical variants of the paranasal sinuses. Oman medical journal. 2014;29(2):110-13.

54. Amusa YB, Eziyi JA, Akinlade O, Famurewa OC, Adewole SA, Nwoha PU, Ameye SA. Volumetric measurements and anatomical variants of paranasal sinuses of Africans (Nigerians) using dry crania. Int J Med Med Sci. 2011;3(10):299-303.

55. Adeel M, Rajput MS, Akhter S, Ikram M, Arain A, Khattak YJ. Anatomical variations of nose and para-nasal sinuses; CT scan review. J Pak Med Assoc. 2013;63(3):317-319.

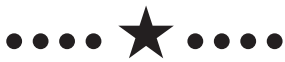

